\title{
Opinion
}

\section{Legalities in All Wound Care Negligence of Care}

\author{
Lydia A. Corum, RN, MSN, CWCN* \\ Wound Care Program Director \\ "Corresponding author \\ Lydia A. Corum, RN, MSN, CWCN \\ Wound Care Program Director; E-mail: lydia.meyers317@gmail.com
}

Article information

Received: November 23 ${ }^{\text {rd }}, 2020$; Revised: January 16 ${ }^{\text {th }}, 2021$; Accepted: January $21^{\text {st }}, 2021$; Published: February $3^{\text {rd }}, 2021$

\section{Cite this article}

Corum LA. Legalities in all wound care negligence of care. Emerg Med Open J. 202 I; 7(I): 7-8. doi: 10. I7I 40/EMOJ-7-I59

$\mathrm{W}$ ound care costs in the United States exceeds 10 times more than that of other countries. ${ }^{1}$ Legal suites are increasingly paid out by clinicians, not the hospitals or the healthcare system. ${ }^{2}$ Many clinicians are facing lawsuits for malpractice or professional neglect. When taken to court and found guilty, the judgment will result in a large settlement then include the loss of the clinician's license. ${ }^{1}$ Since malpractice has a limited judgement, many lawyers are seeking damages as a result of elder abuse. In using elder abuse, the judgements do not have a limitation and often result in very large settlements. ${ }^{2}$ Clinicians need to learn how to protect him/ herself from lawsuits and present the best defense. Areas of negligences in care are: 1) Failure to follow the provider's orders. 2) Failure to properly monitor and observe the patient and the progress of the wound, 3) Failure to report changes in the patient's condition. 4) Failure to properly document wound assessment properly and with true description. ${ }^{2}$ The following paragraphs will explain these failures in greater detail.

Failure to follow a doctor's order can result in disciplinary action by the employer and board of nursing. ${ }^{3}$ There are exceptions, when related to patient safety or against hospital policy. The difference between medication orders and wound care, is the fact the patient is seldom at a safety risk or not following hospital policy. ${ }^{3}$ The failure of not following a wound care order, could result in the wound not healing properly. An example of a discharge order: "After cleansing the sacral wound, with wound cleanser, pack lightly with Aquacel, cover with Mepilex Sacral, change every 2-days or as needed if greater than 50\% drainage or an episode of incontinence." Once the discharging agency receives the order, a nurse is sent out to evaluate the wound and do the dressing change. What is discovered, is the orders are very specific in the dressing types and none are what the discharging agency has in stock. ${ }^{4}$ The nurse substitutes the products and leaves a message for the doctor. Talks with the family and explains what has done and that this will not affect the healing. The nurse substituting products is disregarding orders and could be found negligent if the wound worsened and the family/patient did not understand why the substitution. This nurse did right and needs to document exactly what was done at the time of the visit. A better order would be to use generic names and allow superstitions. ${ }^{4}$ Writing dressing orders, needs to have all information, and treatment products be in generic, if possible. The orders need to specify: location of wound, type of wound, type of primary dressing, if packed location of packing, if tunnel present, what to pack in tunnel, how to address undermining, the secondary dressing, how often to change, and what to do if there is changes in the wound, dressing soiled or not available. ${ }^{5}$ This allows the person doing the dressing change to know exactly what to do without questions. With each dressing change the wound needs to be monitored and observed for changes and need to change the dressing. ${ }^{6}$

Failure to properly monitor and observe the patient and wound during the shift is a serious infraction of patient safety. ${ }^{7}$ When reading the order for the dressing change, if dated and not due for change, then note in chart: dressing due to be changed on $\mathrm{X}$ date, current dressing in place, surrounding area without signs of infection, patient does not express any signs of pain or discomfort. ${ }^{6}$ Talked with the patient and family about the wound progress and when dressing due for changing. No questions at this time. With each dressing change there must be documentation to include: amount of drainage, signs of infection, odor, amount of slough or eschar located in the wound, and that the dressing was changed as ordered, if not why and that physician is called to report any changes or problems. ${ }^{6}$ Measuring and picturing the wound needs to be made weekly, changes in the wound, on admit, and on discharge. ${ }^{8}$ If the wound is deteriorating or worsening, then family, patient, doctor and wound care specialist need to be called and informed. Then documentation becomes very important to acknowledge increased interventions in place and give explanations of what is happening to cause the deterioration. Deterioration of a wound could be related to wrong diagnosis, poor nutrition, change in patient physical or mental condition, or possible infection. ${ }^{2}$ 
These factors are all important in wound healing. Often with diabetic wounds, the infection can come on quickly and with systemic signs by the patient. The failure of documenting these observations is crucial not only related to lawsuits, but also need to inform the rest of the team what is going on with the wound.

Failure to documentation appropriately is the cause of the largest amount of lawsuits. Documentation is a way of corresponding with other medical personnel, taking care of the patient. ${ }^{7}$ Documentation related to wound care supports what the wound looked like on admission, with each assessment, and on discharge. ${ }^{9}$ The pictures of the wound only helps assure the picture is presented appropriately. Pictures need to be dated, with the ruler present and only identified by the hospital identity document (ID) numbers or initials of the patient. ${ }^{8}$ The documentation needs to include: diagnosis of the wound and of the patient, the size and depth of the wound, description of undermining and tunneling, treatments being used, any surgeries or special procedures done, pain, plan of care and when next treatment to be done. If the wound continues to heal, documentation to how the patient and family are notified of progress and any questions. ${ }^{10}$ If the wound deteriorates, what actions are taken, what has changed with the patient and changes in the diagnosis. Who was notified of the changes and when. How long the treatment will need to continue. All this information must be given to the patient and/or family. Informing and educating is very important to assure there is compliance and understanding of the plan of care. ${ }^{7}$

Negligence is mentally, physically, and financially exhausting. The wound care clinician needs to be aware of the ways to protect him/herself. Certification presents credibility to the clinician. National certification is designed to show credible education and criteria has been followed to receive this accreditation. Making a checklist to assure the certification is credible will assure money well spent. ${ }^{5}$ To assure a standard of care is maintained, a clinician should educate him/herself by attending seminars, conversations and belonging to organizations. ${ }^{2}$ Stay educated about state policies, procedures and standard of practice. Never criticize the doctors, nurses, or the facility you work with or for. Maintain professionalism when taking care of patients and working with staff. This all helps to decrease the chances that you will be involved in a law suite. It is important that the patient and family have respect for you and what you do. ${ }^{2}$

\section{REFERENCES}

1. Croke EC. Nurses, negligence, and malpractice. Am J Nurs. 2003; 103(9):54-63. quiz 64. doi: 10.1097/00000446-200309000-00017

2. Jakucs C. Substandard wound care can create legal risks for nurses. 2019.Web site. www.nurse.com/blog/2019/06/13/substandard-wound-care-create-legal-risks-nurses/. Accessed November 22, 2020.

3. RegisteredNursing.org Staff. Does a Nurse Always Have to Follow a Doctor's Order? Web site. www.registerednursing.org. Accessed November 22, 2020.

4. Ubbink DT, Brölmann FE, Go PMNYH, Vermeulen H. Evidence-based care of acute wounds: A perspective. Adv Wound Care (New Rochelle). 2015; 4(5): 286-294. doi: 10.1089/wound.2014.0592

5. Bryant Ruth, Nix DP. Acute and Chronic Wounds: Current Management Concepts. Amsterdam, Netherlands: Elsevier; 2016.

6. Baranoski S, Ayello EA. Wound Care Essentials: Practice Principles. aan den Rijn, Netherlands: Wolters Kluwer; 2016.

7. Hess CT. Understanding your documentation requirements. Adv Skin Wound Care. 2018; 31(3): 144. doi: 10.1097/01. ASW.0000530374.61754.a3

8. Jakucs C. Legal issues clinicians should know when taking wound care pictures. 2020. Web site. blog.wcei.net/2019/04/legal-issuesclinicians-should-know-taking-wound-care-pictures. Accessed November 22, 2020.

9. Fife CE, Carter MJ. Wound care outcomes and associated cost among patients treated in us outpatient wound centers: Data from the us wound registry. Wounds. 2012; 24(1): 10-7.

10. Moore GP, Pfaff JA. Malpractice cases in wound care and a legal concept: special defense. West J Emerg Med. 2008; 9(4): 238-239. 